\title{
EXTRINSIC AND INTRINSIC CONTROLS OF ZOOPLANKTON DIVERSITY IN LAKES
}

\author{
Dag O. Hessen,,${ }^{1,5}$ BjøRn A. FaAfeng, ${ }^{2}$ Val H. Smith, ${ }^{3}$ Vegar Bakkestuen, ${ }^{4}$ And Bjørn Walseng ${ }^{4}$ \\ ${ }^{1}$ University of Oslo, Department of Biology, P.O. Box 1027 Blindern, N-0316 Oslo, Norway \\ ${ }^{2}$ Norwegian Institute for Water Research, P.O. Box 173 Kjelsås, N-0411 Oslo, Norway \\ ${ }^{3}$ Department of Ecology and Evolutionary Biology, University of Kansas Lawrence, Kansas 66045 USA \\ ${ }^{4}$ Norwegian Institute for Nature Research, P.O. Box 736 Sentrum, N-0105 Oslo, Norway
}

\begin{abstract}
Pelagic crustacean zooplankton were collected from 336 Norwegian lakes covering a wide range of latitude, altitude, lake area, mean depth, production (as chlorophyll a), and fish community structure. Mean zooplankton species richness during the ice-free season was generally low at high latitudes and altitudes. Further, lower species richness was recorded in western lakes, possibly reflecting constraints on migration and dispersal. However, despite obvious spatial limitations, geographic boundaries were only weak predictors of mean zooplankton richness. Similarly, lake surface area did not contribute positively to mean richness such as seen in other ecosystem surveys. Rather, intrinsic factors such as primary production and fish community (planktivore) structure were identified by regression analysis as the major predictors of zooplankton diversity, while a positive correlation was observed between species richness and total zooplankton biomass. However, in spite of a large number of variables included in this study, the predictive power of multiple regression models was modest $(<50 \%$ variance explained), pointing to a major role for within-lake properties, as yet unidentified intrinsic forces, stochasticity, or dispersal as constraints on zooplankton diversity in these lakes.
\end{abstract}

Key words: altitude; biodiversity; fish; lake area; latitude; longitude; production; species richness; zooplankton.

\section{INTRODUCTION}

Although the distribution of biodiversity across the Earth can be described in terms of a relatively small number of spatial patterns such as latitude, altitude, or habitat size, understanding how these extrinsic drivers influence diversity remains one of the most significant intellectual challenges to ecologists and biogeographers (Gaston 2000). A large number of studies, covering a wide variety of ecosystems and organisms, suggest that species richness tends to vary strongly with ecosystem production and habitat heterogeneity (Rosenzweig 1995). However, as habitat heterogeneity also can co-vary with production, the role of niche diversity per se may not be separated easily from other causal factors. As pointed out by Hutchinson (1959) and many others, studies of plankton diversity are particularly intriguing because both autotrophs and heterotrophs are thought to share a fairly homogenous habitat within the pelagic zone. Most herbivorous, pelagic metazoans also share a restricted size range of food, and many of the key cladoceran grazers feed rather nonselectively on phytoplankton and other sestonic particles. Hence, niche differentiation should be modest, at least among truly pelagic species in large water bodies.

Manuscript received 2 March 2005; revised 28 June 2005; accepted 28 July 2005. Corresponding Editor: P. R. Leavitt.

${ }^{5}$ E-mail: dag.hessen@bio.uio.no
After decades of research, there is still no consensus on the specific shape of the relationship between production and diversity (Chase and Ryberg 2004). This function sometimes increases monotonically (Browne 1981, Currie 1991, Rosenzweig 1995, Mittelbach et al. 2001), although a concurve downwards function with maximum consumer diversity occurring at medium production is also commonly observed (Waide et al. 1999, Dodson et al. 2000, Gatson 2000, Irigolen et al. 2004). Chase and Leibold (2002) have suggested that such discrepancies in response could be attributed to variations in the spatial scale of study. For example, both autotroph and consumer richness in ponds may exhibit a unimodal relationship to production at a local scale (among ponds), while at a regional scale (among watersheds), species richness increases linearly with production. Thus the unimodal relationship between species number and production reported in several lake and pond surveys (Leibold 1999, Dodson et al. 2000) could be due, in part, to a limited geographical range of their studied localities (cf. Chase and Leibold 2002) or to variations in inter-system connectivity and metacommunity structure (Chase and Ryberg 2004).

While the bottom-up effects of primary production on diversity have been well explored, there have been relatively few studies of predator (top-down) effects on species diversity (reviewed in Proulx and Mazumder 1998). While it has been well documented that the removal of competitively superior species by predation 
may reduce competition and thus promote species coexistence (Paine 1966, Chase et al. 2002), the extent to which predation may promote zooplankton diversity is uncertain. For example, although Mittelbach et al. (2004) found experimental evidence for increased resource availability per consumer under intense predation regimes, these increases did not affect either species richness or species evenness. In addition, other richness-independent abiotic parameters such as disturbance (Hutchinson 1959, Connell 1978, Flöder and Sommer 1999) and lake size (Browne 1981, Fryer 1985, Dodson 1992, O'Brien et al. 2004) can also influence aquatic species diversity. Further, because both biotic and abiotic controls may vary in intensity along geographic gradients such as altitude and latitude, species richness may exhibit strong biogeographical patterns of occurrence, although this factor has rarely been explored.

We address these issues in this study by analyzing spatial patterns of pelagic crustacean species diversity in 336 Norwegian lakes covering a wide span in geographical range, latitude and altitude, lake size, production, and fish community composition. We hypothesized that there would be opposing effects on species diversity of lake production and predation by planktivorous fishes, as found elsewhere (Worm et al. 2002, Hillebrand 2003). Given the strong bias towards nutrient-poor lakes in this study, we expected that species richness should exhibit a unimodal relationship with production. Further, because of strong spatial gradients of lake elevation and climate, we anticipated that species richness should exhibit strong biogeographic boundaries. Specifically, we expected a strong negative correlation between species diversity and both altitude and latitude, due to a combination of decreased lake temperature, shorter growth season and, potentially, reduced dispersal ability.

\section{Materials And Methods}

\section{Study sites}

This research was based on a large survey of Norwegian lakes (Hessen et al. 1995, 2003), wherein data from an initial pool of 400 lakes were collected at least four times during the ice-free season (May-September). However, some lakes were not included in the final analysis, either because of incomplete information of fish community composition (60), high salinity (three), or extremely high levels of $\mathrm{P}$ and mineral turbidity (one). Of the 336 remaining lakes, most sites $(87 \%)$ were sampled for two or three years, 44 lakes for four years, and only five lakes for five or six years.

Overall, study lakes represented a range of trophic status from oligotrophy to eutrophy (total phosphorus, TP, 1.4-655 $\mu \mathrm{g} / \mathrm{L}$ ), although most sites fell below 15 $\mu \mathrm{g}$ TP/L. Although the lakes spanned a surface area from 0.06 to $210 \mathrm{~km}^{2}$, the survey also included the 20 largest Norwegian lakes, while $94 \%$ of the lakes had a surface area $>1 \mathrm{~km}^{2}$ (average $7.7 \mathrm{~km}^{2}$ ). The lakes were located at latitudes from ranging $65^{\circ} \mathrm{N}$ to $77^{\circ} \mathrm{N}$ and from sea level to $1058 \mathrm{~m}$ above sea level (asl). Acidic lakes $(\mathrm{pH}<5.5)$ were avoided, as were three seawater-influenced lakes such that there were no sites with conductivity $>50 \mathrm{mS} / \mathrm{m}$. While the majority of catchments were dominated by coniferous forest, human impacts were evident at most sites, with the highest levels of $\mathrm{P}$ and $\mathrm{N}$ recorded in lakes associated with agricultural activities. We obtained average temperatures from May through September for 184 lakes covering the entire longitudinal gradient and for which meteorological data were available from nearby monitoring stations. All these lakes were situated $<250 \mathrm{~m}$ asl.

All water-column sampling was performed with a 10-L, clear, flexible hose with an internal diameter of $10 \mathrm{~cm}$. Integrated samples were taken from the trophogenic zone, defined as twice the Secchi disc transparency of the lake. Overall, mean sampling depth was $\sim 10 \mathrm{~m}$. Total phosphorus, chlorophyll a $(\mathrm{chl} a)$, and phytoplankton biovolume were analyzed from integrated samples. TP was quantified using a flow injection autoanalyzer (FIAstar 5020 Analyzer, Tecator AB, Sweden) after persulfate digestion, whereas chl $a$ was measured spectrophotometrically after acetone extraction. TP, chl $a$, and phytoplankton biovolume were highly correlated $\left(r^{2}>0.7, P<0.0001\right)$; however, owing to the problems with adequate counting of picoplankton by the Utermöhl techniques, we used chl $a$ as a proxy for lake production (cf. Smith 1979).

\section{Zooplankton methods}

All species and stages of pelagic crustaceans were isolated from a $10-\mathrm{L}$ pooled sample from the trophogenic zone that had been concentrated onto $45-\mu \mathrm{m}$ mesh netting. Rotifer numbers and biomass were analyzed from the same sample, but complete species identifications were not performed for this group and the species richness values reported in this study do not include rotifers and unicellular heterotrophs. On average, rotifer biomass contributed only $\sim 10 \%$ of total metazoan biomass.

Species diversity in each lake was estimated as the grand mean of richness recorded on all sampling dates across all years to avoid potential bias caused by variations in sampling intensity (cf. Arnott et al. 1998, Gotelli and Colwell 2001). Since species turnover is expected during ecologically relevant time scales, and because transient taxa may also occur in single samples, we believe this average of multiple samples provides a more robust representation of species diversity than do single observations or cumulative species lists. This approach also minimizes problems associated with unequal sampling periods and frequencies, even though the majority of lakes were sampled uniformly on four occasions during a single season. This metric is equivalent to species density as defined by Gotelli and Col- 
well (2001) and is always lower than estimates of maximum summer richness or cumulative richness, or those based on studies in which benthic sampling is also included. However, because sampling of euphotic species richness was based on the same depth intervals as those for estimates of lake production (TP, chl $a$ ), such restricted estimate of diversity should facilitate identification of mechanisms regulating overall species richness.

The taxonomic identities of some zooplankton remained incompletely resolved. For example, within Daphnia group, D. longispina s. str. were grouped with $D$. rosea and alpine $D$. umbra, two unique taxa recently identified by analysis of mitochondrial DNA and nuclear markers (Hobæk 2005). Also some Daphnia species (e.g., D. galeata) can hybridize with other daphnids (Schwenk et al. 2000, Hobæk et al. 2004), rendering definitive taxonomic identification problematic. Although genetic screening will likely reveal further taxonomic revisions, such problems should not bias our ability to identify the presence of substantial gradients of species diversity because all samples were collected and enumerated using the same protocol.

Zooplankton biomass was determined from empirical regressions relating body morphology to dry mass for copepods and cladocerans (Dumont et al. 1975, Bottrell et al. 1976). In contrast, a fixed mean mass was assumed for each rotifer species, as well as for immature calanoid and cyclopoid nauplii. For all cladocerans and advanced stages of copepods, total body length was measured either for all individuals present in the sample or for a representative subsample of more than 20 individuals in case of large numbers.

Estimates of fish species composition were classified based on reports, questionnaires, or local catch data. Four functional community classes were identified, representing a gradient of increasing predation pressure on zooplankton (cf. Hessen et al. 1995): class 1 lakes contained only brown trout (Salmo trutta) $(n=43)$; class 2 lakes contained Arctic char (Salvelinus alpinus) or perch (Perca fluviatilis) as dominant species $(n=$ 100); class 3 lakes contained whitefish (Coregonus lavaretus) or stickleback (Gasterosteus aculeatus) as dominant species $(n=106)$; and class 4 communities were composed mainly of cyprinids with roach (Rutilus rutilus), bleak (Alburnus alburnus), rudd (Scardinius erythrophthalmus), or dace (Leuciscus leuciscus) $(n=$ $65)$. In general, these classifications also corresponded to a gradient of lake production, from oligotrophic lakes (classes 1 and 2), to mesotrophic (class 3) and eutrophic lakes (class 4). Reliable data on fish biomass was available for a few lakes only, and thus not included in this analysis.

\section{Statistical methods}

Covaration and multicollinearity are notorious problems in multifactor ecosystem studies (Graham 2003). In particular, significant positive correlations are com- mon large data sets, although relations among parameters may have very low explanatory power. We used three approaches to reduce the problem of collinearity. First, we avoided comparisons of obvious covariates such as chl $a$ and TP as indices of primary production. Second, we used principal components analysis (PCA) to identify independent predictors of species richness. Finally, PCA results were applied to multiple linear regression models to possible redundancy among environmental predictors of species richness.

Principal component analysis was performed on the set of 15 predictor variables following ter Braak and Prentice (1988) using CANOCO v. 4.5 (ter Braak and Smilauer 2002). PCA was run on a correlation matrix of centered, standardized and transformed variables using correlation biplot scaling of PCA axes. Species richness variables were added by passive ordination to identify possible relationships between diversity and lake characteristics. Skewness and kurtosis were standardized for all predictor variables by dividing by their expected deviations, estimateds $(6 / n)^{0.5}$ (Sokal and Rohlf 1995). Homogeneity of variance (homoscedasticity) was achieved by transforming all variables to zero skewness. Three transformations were applied (Økland et al. 2001):

$$
\begin{aligned}
& y_{k j}^{\prime}=e^{c_{k} x_{k j}} \\
& y_{k j}^{\prime}=\ln \left(c_{k}+x_{k j}\right) \\
& y_{k j}^{\prime}=\ln \left(c_{k}\right)+\ln \left(c_{k}+x_{k j}\right)
\end{aligned}
$$

where $x_{k j}$ is the original value of variable $k$ in plot $j$ and $c_{k}$ is a variable specific parameter that gives the transformed variable $Y^{\prime}=\left\{y_{k j}^{\prime}\right\}$ zero skewness. The first transformation is applied to left-skewed variables (standardized skewness $<0$ ), the next equation to rightskewed variables. The last transformation was applied to right-skewed variables for which no $c_{k}$ could be found by the middle equation that resulted in standardized skewness $=0$. After transformation, all variables $Y^{\prime}$ were ranged to obtain new variables $Y=\left\{y_{k j}\right\}$ on a $0-1$ scale:

$$
y_{k j}=\left[y_{k j}^{\prime}-\min \left(y_{k j}^{\prime}\right)\right] /\left[\max \left(y_{k j}\right)-\min \left(y_{k j}\right)\right] .
$$

Least-squares linear regressions were performed between the mean species richness of zooplankton crustaceans and the major candidate independent variables as judged from preliminary PCA. Predictors used in a full-model regression analysis included lake altitude, latitude and longitude, surface area, maximum depth, area:maximum depth ratio, lake production $(\operatorname{chl} a)$, calcium ion concentration, and lake color. However, based on evidence of collinearity from PCA, a multiple linear regression model was run also using only latitude, altitude, lake area, maximum depth, chlorophyll $a$ concentration, calcium concentration, and fish community class as independent variables. Both backward and forward selection procedure were used to add $(P=0.25)$ 

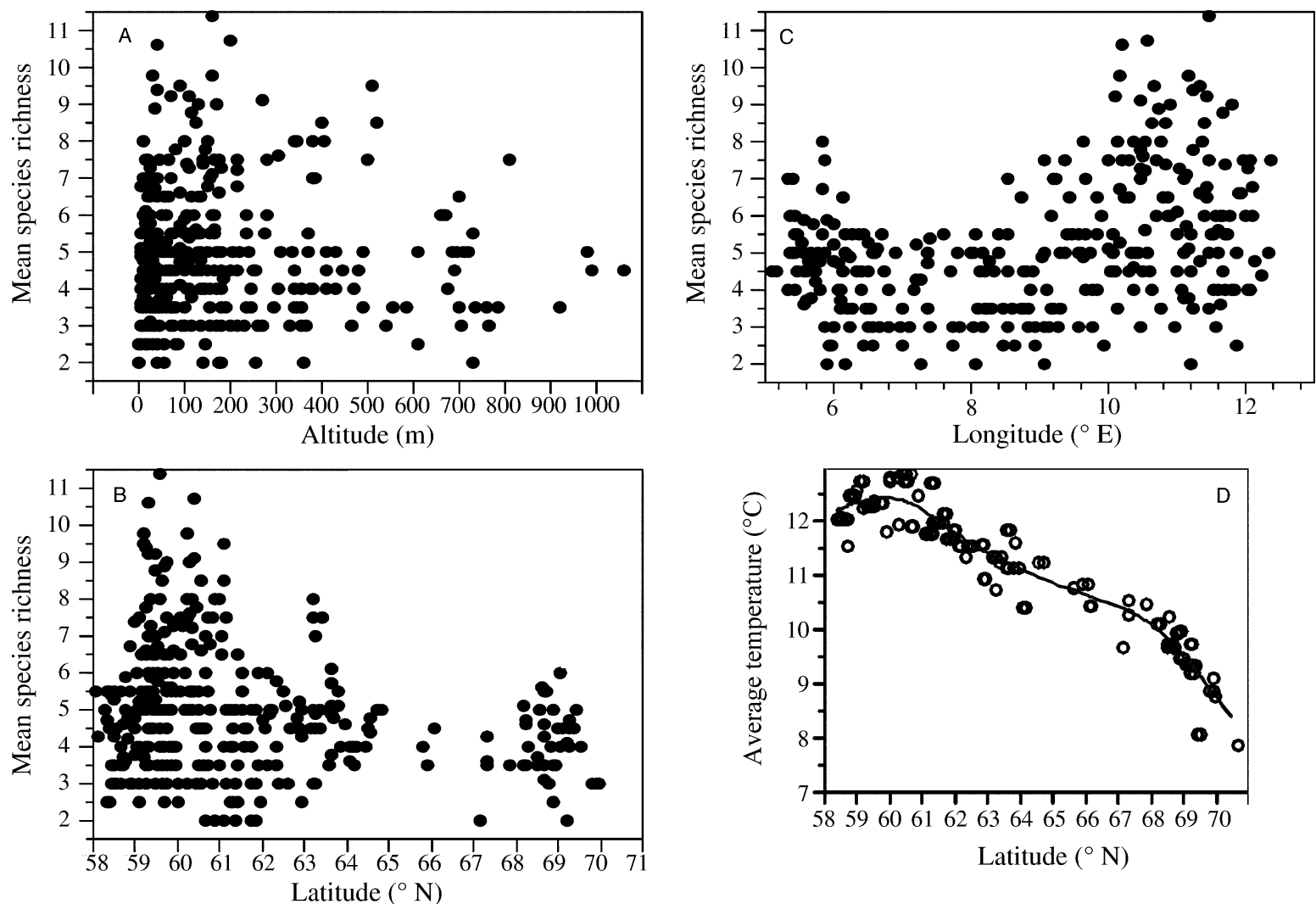

FIG. 1. Scatterplot of mean species richness of crustacean zooplankton vs. (A) altitude, (B) latitude, and (C) longitude. The data for altitude and latitude are for the entire data set covering the Norwegian mainland, while longitude is for the central (and wide) part of Norway $\left(59-61^{\circ} \mathrm{N}\right.$ ), covering a transect from $5^{\circ}$ to $12^{\circ} \mathrm{E}$. Panel (D) shows a smoothed spline fit of average temperature for 184 lowland lakes covering the latitudinal gradient.

or remove $(P=0.1)$ to regression models, although there was no difference in final model selected. Finally, we performed separate linear regressions of species richness against all individual parameters to test for effects of single parameters separately. Parameters with nonnormal distributions were $\log _{10}$ transformed, whereas fish community structure was analyzed as a categorical variable. Because fish class 4 did not occur north of $65^{\circ} \mathrm{N}$ and rarely in lakes above $300 \mathrm{~m}$ altitude, we also performed a test for a subset of the lakes where high altitude ( $>300 \mathrm{~m}$ above mean sea level) and northern lakes $\left(>65^{\circ} \mathrm{N}\right)$ were excluded from the analysis (245 lakes remaining). All regression analyses were performed with JMP 5.1 (SAS Institute, Cary, North Carolina, USA).

\section{RESULTS}

\section{Abiotic factors}

The lakes analyzed in this study spanned a wide range of altitudes (from $1 \mathrm{~m}$ to $\sim 1100 \mathrm{~m}$ asl) and latitudes $\left(58.1-70.7^{\circ} \mathrm{N}\right)$. Lakes at low altitudes and latitudes exhibited a wide range of zooplankton species richness, while alpine and subarctic lakes usually contained fewer than eight species (Fig. 1). However, ow- ing to strong variability in species richness in lakes at low altitudes and latitudes, there were no significant effects of these two geographic parameters on diversity, regardless of whether northern and high-altitude lakes were included in the analysis. For lowland areas $(<250$ $\mathrm{m})$ the average summer temperature reflected the latitudinal decline in irradiation (Fig. 1D).

Zooplankton species richness also exhibited a longitudinal pattern within central Norway, with comparatively low diversity in western lakes located between 59 and $61^{\circ} \mathrm{N}$ (Fig. 1C). To some extent this pattern reflects the general topography of Norway, where alpine areas occur primarily between 6 and $8^{\circ}$ E. However, the low number of crustacean zooplankton species in western low-latitude lakes was striking when compared with similar boreal lakes in eastern regions.

Somewhat surprisingly, species richness was inversely correlated both with lake surface area $\left(r^{2}=\right.$ $\left.0.04, F_{1,347}=13.9, P<0.001\right)$, and with lake maximum depth $\left(r^{2}=0.11, F_{1,319}=39.5, P<0.0001\right)$, but not with surface area:maximum depth ratios $\left(r^{2}=0.003\right.$, $P=0.3$ ) (Fig. 2, Table 1). There was no significant correlation between lake area and altitude or latitude, suggesting that the slight negative effect of lake area 

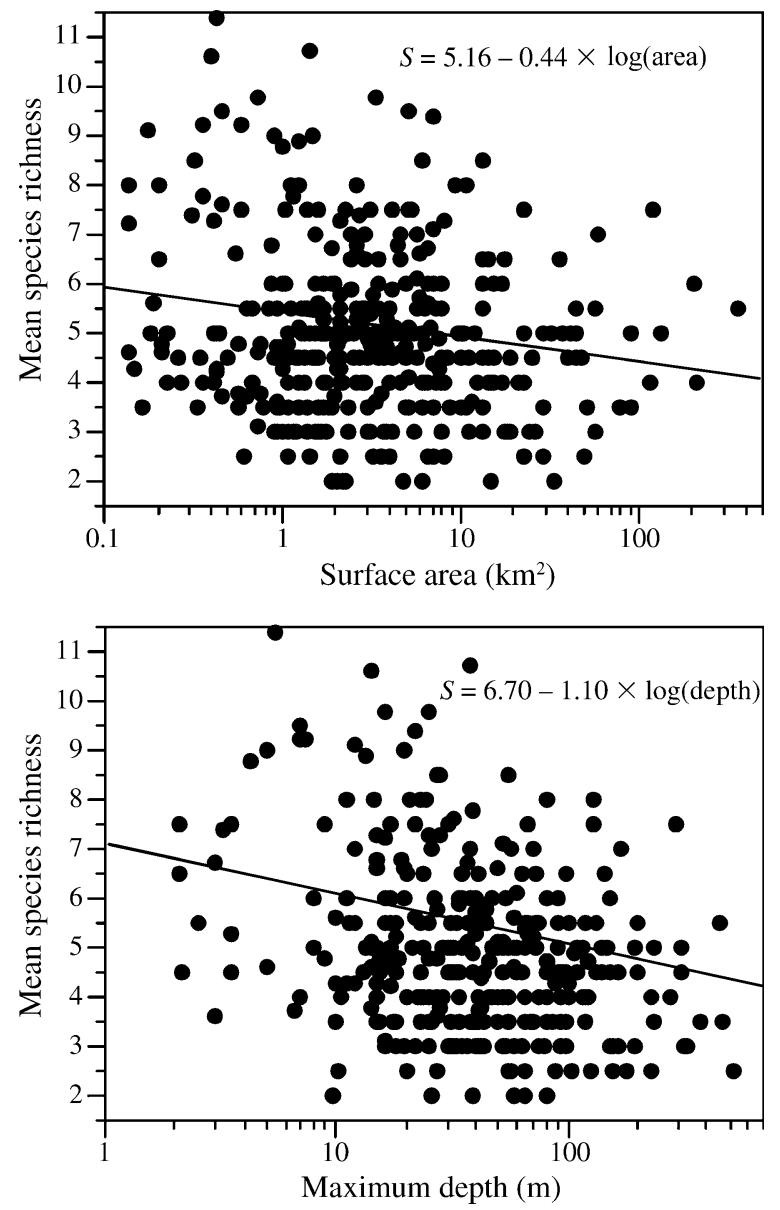

FIG. 2. Mean species richness of crustacean zooplankton vs. lake surface area and maximum depth; the least-squares regression line is shown. Note the $x$-axis log scale.

cannot be attributed to variation in these two parameters. In support of this view there were no significant interaction between lake area and altitude $(P=0.07)$ or area and latitude $(P=0.30)$ in the multiple regression analyses.

\section{Biotic factors}

There was a weak tendency for production (as TP or chl a) to decline with increasing latitude and altitude. Instead, we recorded an unexpected but significant negative correlation between chl $a$ and lake area (Table 1). In general, concentrations of chl $a$ differed significantly among fish classes $(P<0.05$, pairwise $t$ test $)$, while fish class 4 was significantly less abundant at high altitudes and latitudes.

Zooplankton species richness was positively correlated with production as measured by $\operatorname{chl} a(P<0.001$; Table 1 and Fig. 3). Regression analyses also revealed a positive correlation between zooplankton richness and total zooplankton biomass (Table 1 and Fig. 4), in part reflecting the fact that zooplankton biomass was positively correlated with chl $a$. Multiple regression analysis of diversity revealed that species richness was positively correlated with both zooplankton mass and chl $a(P<0.0001)$, although there was no significant interaction among predictors $(P=0.17)$. When applying the fish community categories as nominal variables, there was a significant effect of fish community composition on species richness, with higher richness of total species and cladocerans in fish class 4 , the category assumed to represent the greatest predation pressure by vertebrate zooplanktivores (Fig. 4).

\section{Principal component analysis}

The first (PCA1) and second (PCA2) axes were both significant and explained $32.5 \%$ and $18.6 \%$ of observed variance in environmental variables, respectively (Fig. 5). Chl $a$, TP, and total nitrogen (TN) exhibited high positive loadings on PCA1, while lake depth and area were negatively correlated with this axis. Consequently, PCA1 can be interpreted as a gradient of production that increased as lake depth, area, altitude, and latitude declined. In contrast, fish community structure (as functional classes) was strongly correlated with PCA2, increasing as latitude declined. Thus, the second axis records mainly a gradient in fish composition, largely independent from lake production $(\operatorname{chl} a)$. Thus, when

TABLE 1. Least-squares linear regression models relating species richness $(S)$ and chlorophyll $a(\operatorname{chl} a)$ to key environmental parameters at significance levels of $P<0.05$.

\begin{tabular}{lcccc}
\hline \hline \multicolumn{1}{c}{ Model } & $r^{2}$ & $\mathrm{df}$ & $F$ & $P$ \\
\hline Mean zooplankton species richness & & & & \\
$S=3.95+2.01 \times \log (\operatorname{chl} a)$ & 0.22 & 1,347 & 98.4 & $<0.0001$ \\
$S=1.88+1.72 \times \log$ (ZooMass) & 0.21 & 1,347 & 95.1 & $<0.0001$ \\
$\log$ (ZooMass) $=1.18 S+1.12$ & 0.21 & 1,347 & 95.1 & $<0.0001$ \\
$S=3.25+1.80 \times \log ($ total P) & 0.14 & 1,347 & 57.9 & $<0.0001$ \\
$S=12.88-0.13$ (latitude) & 0.06 & 1,347 & 21.3 & $<0.0001$ \\
$S=5.18-0.59 \times \log ($ area) & 0.04 & 1,347 & 14.9 & $<0.0001$ \\
Chlorophyll $a$ & & & & \\
$\log (\operatorname{chl} a)=0.64-0.32 \times \log ($ area) & 0.23 & 1,347 & 111.2 & $<0.0001$ \\
$\log (\operatorname{chl} a)=0.73-0.13 \times \log ($ altitude) & 0.04 & 1,347 & 15.9 & $<0.0001$ \\
$\log (\operatorname{chl} a)=1.73-0.02$ (latitude) & 0.03 & 1,346 & 10.7 & $<0.0001$ \\
\hline
\end{tabular}

Note: Parameters with highly skewed distributions were $\log _{10}$-transformed. 


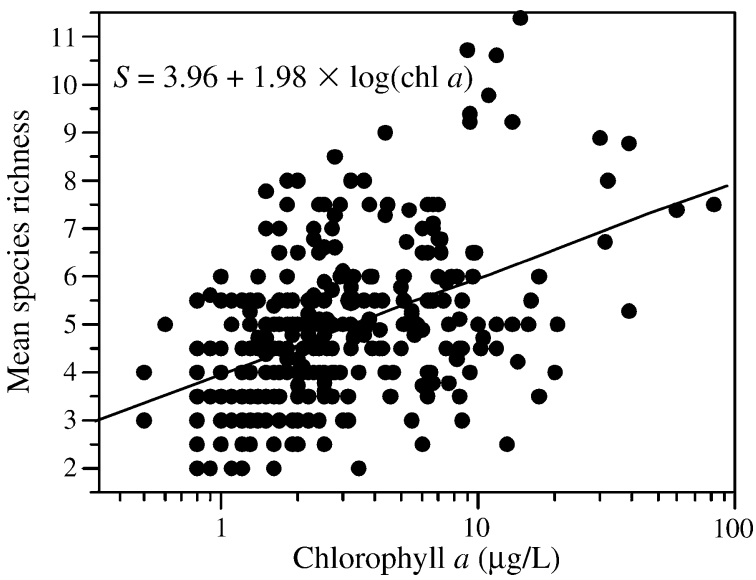

FIG. 3. Mean species richness of crustacean zooplankton vs. chlorophyll $a$; the least-squares regression line is shown.

species richness variables were added passively to the PCA ordination, zooplankton diversity appeared to be strongly related to PCA1, the main gradient of lake production. However, slight differences in ordination between copepods and cladocerans suggest that the latter are also influenced by fish community structure. In general, species richness variables were negative correlated with latitude and lake depth, area, and altitude.

\section{Multiple linear regression}

Based results of PCA ordinations (Fig. 5), altitude, latitude, longitude, chl $a$, zooplankton biomass, and fish community structure were selected as initial input parameters for the multiple linear regression model. However, only zooplankton biomass remained as a significant predictor in a model that explained $49 \%$ of the variability $(P<0.0001)$ in mean crustacean species richness (Table 2). Further, because zooplankton biomass was strongly correlated to lake production, a second analysis was conducted without zooplankton biomass to remove the collinearity between zooplankton mass and diversity. In this case, chl $a(P<0.0001)$ and fish community composition $(P=0.042)$ were retained as significant predictors of mean zooplankton richness, while $R^{2}$ was reduced to 0.39 . In addition, there was no significant $\operatorname{chl} a \times$ fish interaction in the modified model, suggesting independent contributions from both production and fish. As expected, simple linear regression analysis revealed that mean cladoceran species richness was correlated to both chl $a$ and fish community structure $(P<0.001)$, whereas lake production alone contributed to copepod diversity and $\operatorname{chl} a \times$ fish interactions were not significant for either group. Finally, regression models for the 245 lakes that excluded northern $\left(>65^{\circ} \mathrm{N}\right)$ and high elevation sites $(>300 \mathrm{~m}$ asl $)$ explained $43 \%(P<0.0001)$ of species richness when zooplankton biomass was excluded from analysis (Table 3). Again, chl $a$ was as a strong predictor $(P<0.001)$ of zooplankton diversity, although fish community composition did not contribute significantly in this subset.

\section{DISCUSSION}

\section{Landscape patterns of diversity}

Analysis of this large number of Norwegian lakes revealed that mean zooplankton species richness was constrained by variations in lake latitude and altitude, i.e., high latitude and altitude lakes had always low richness. Longitudinal boundaries on richness were most pronounced in central Norway, where eastern lakes had higher species richness than western lowlands areas, with very low richness in the mountain ridges that separates the eastern and western localities. However, despite these obvious boundaries, geographic parameters were poor predictors of absolute richness, since low altitude and latitude lakes spanned the entire large of zooplankton diversity (Fig. 1). Instead, other extrinsic variables such as solar irradiation, temperature, and length of growing season may have influenced the species richness of pelagic cladocerans (e.g., Fig. 1D). In addition, these geographical variables may also correspond to migration barriers and colonization constraints.

It is difficult to distinguish among immigration, climate or other spatially structured constraints as causes of geographic patterns in richness. The fact that most zooplankton have wide geographical distribution and moderate to good colonization abilities (Shurin 2000, Jensen et al. 2001), combined with long period for colonization since the last period of glaciation $(\sim 8000$ $\mathrm{yr}$ ), suggests that the relatively low diversity observed in western lakes (65\% relative to eastern sites) arises from some biological controls of diversity, rather than on the inability of species to reach potential habitats (Havel and Shurin 2004). There are no clear biological or physical properties of these lakes that should make them less suitable for colonization; in fact, the mild western coastal climate should actually be expected to promote successful colonization.

Since immigration of most freshwater species has been westwards and northwards from continental Europe since the end of the last glaciation (Refseth et al. 1998, Hewitt 2000, Hobæk et al. 2002), observed geographic pattern of species richness suggest that western and northern regions may not yet be saturated with species. Independent analysis of individual species (not shown) demonstrates that there were two major patterns of species distribution. First, some species exhibit a very pronounced geographically constrained distribution, consistent with either low dispersal abilities, climatic constraints, or competitive exclusion. In contrast, other species were broadly represented in all major geographic regions, with presence or absence in specific lakes apparently regulated by intrinsic lake-specific parameters like production, predation, or competition. This suggests that the species that are most 
FIG. 4. Mean species richness of crustacean zooplankton vs. zooplankton biomass with different fish community categories: blue, class 1 ; green, class 2; orange, class 3 ; red, class 4 (see Materials and methods: Zooplankton methods for descriptions of each class). Red line, leastsquare $y$ over $x$; blue line, least-square $x$ over $y$; dashed line, principal component. Note the $x$-axis $\log$ scale.

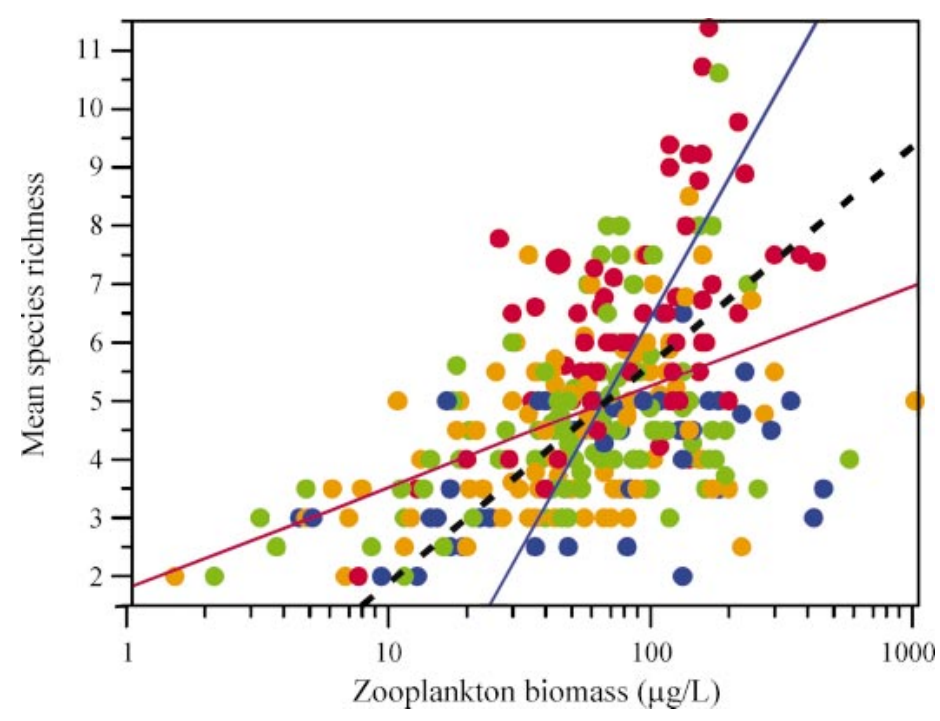

clearly geographically constrained are those with low dispersal rates and colonization abilities, which again suggest that the neutral theory of biodiversity (Hubbel 2001) might have a species-specific relevance.

\section{Species richness and lake area}

Species richness often increases with ecosystem size (Gaston 2000) or lake area (Browne 1981, Fryer 1985, Dodson 1992, Dodson et al. 2000, O’Brien et al. 2004); however, this pattern was not recorded in our survey. Instead, a weak negative correlation of richness with lake size was observed (Fig. 2), possibly due to the fact that both lake area and maximum depth were also negatively correlated with chl $a\left(r^{2}=0.29\right.$ and 0.44 , respectively). This latter observation suggests that lake production, rather than ecosystem morphometry per se, was the primary cause for negative correlations between species richness and lake size. In addition, negative correlations between lake size and zooplankton diversity may arise because sampling of small and shallow lakes will be more likely to include taxa from benthic or littoral habitats, unlike the case in very deep lakes.

The absence of significant positive relationships between zooplankton species richness and lake size did not arise from biased lake selection. For example, there was no positive effect of lake size on mean species richness even after correcting for lake production or

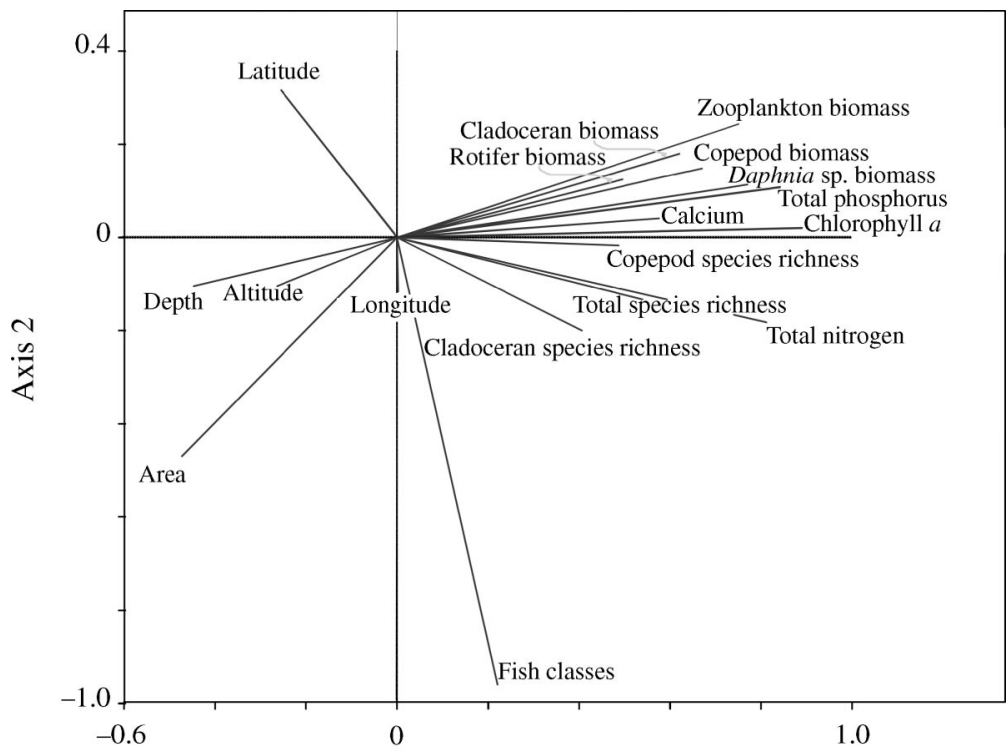

Axis 1

FIG. 5. PCA ordination of 15 environmental variables and three supplementary species richness variables. Tick marks indicate 0.2 units along both axes. 
TABLE 2. Multiple linear regression models to predict species richness from key environmental variables identified from principal components analyses.

\begin{tabular}{lrccc}
\hline \hline \multicolumn{1}{c}{ Source } & ss & df & $F$ & $P$ \\
\hline With zooplankton biomass & & & & \\
$\log ($ ZooMass) & 62.776 & 1,275 & 37.97 & $<0.0001$ \\
Fish & 13.940 & 3,275 & 2.810 & 0.04 \\
$\log ($ chl $a$ ) & 3.390 & 1,275 & 2.050 & $\mathrm{NS}$ \\
Altitude & 0.097 & 1,275 & 0.006 & $\mathrm{NS}$ \\
Latitude & 0.748 & 1,275 & 0.453 & $\mathrm{NS}$ \\
Longitude & 0.872 & 1,275 & 0.527 & $\mathrm{NS}$ \\
$\log ($ area) & 0.255 & 1,275 & 0.154 & $\mathrm{NS}$ \\
Without zooplankton biomass & & & & \\
log(chl $a)$ & 42.100 & 1,284 & 22.370 & $<0.0001$ \\
Fish & 15.680 & 3,284 & 2.780 & 0.041 \\
Altitude & 0.060 & 1,284 & 0.032 & $\mathrm{NS}$ \\
Latitude & 0.709 & 1,284 & 0.377 & $\mathrm{NS}$ \\
Longitude & 2.360 & 1,284 & 1.254 & $\mathrm{NS}$ \\
log(area) & 0.002 & 1,284 & 0.001 & $\mathrm{NS}$ \\
Fish $\times$ longitude & 20.320 & 1,284 & 3.599 & 0.014 \\
Fish $\times \log ($ area) & 19.390 & 1,284 & 3.440 & 0.017 \\
\hline
\end{tabular}

Notes: Analyses include all lakes with (top panel) and without (bottom panel) zooplankton biomass as a predictor. Interactions are included only when $P<0.05$.

when testing within selected subsets of lakes (e.g., only within lowland, oligotrophic, or southern lakes). Further, these patterns are supported by analysis of an independent lake survey in which richness estimates were based on standard net hauls of zooplankton from 1500 northern lakes (B. Walseng, G. Halvorsen, and D. O. Hessen, unpublished manuscript). Once again, there was no significant correlation between lake area and zooplankton species richness.

Exceptions to a general richness-area relationship further suggest that Norwegian lakes are not yet saturated with species (i.e., not in "equilibrium"), either due to constraints on colonization, or because of the presence of local properties that override any habitatsize effect (Whittaker et al. 2001). While both colonization constraints and intrinsic factors may influence zooplankton species richness, the large variability in diversity among sites, even within a fairly homogenous geographical region like southeastern Norway, indeed points to a dominant role for local or intrinsic factors.

\section{Role of lake production}

For most temperate lakes, phosphorus availability is the major determinant of primary production, algal biomass and, presumably, zooplankton species diversity. Such patterns have been recorded by Dodson et al. (2000) for other temperate lakes and are supported by our finding that mean crustacean richness was strongly correlated to both TP and chl $a$. Our study also revealed a positive correlation between chl $a$, crustacean zooplankton richness, and total zooplankton biomass, consistent with bottom-up (production) regulation of food web processes. These production-diversity relationships were observed both for total species richness, as well as for independent analysis of either copepods or cladocerans. Because these two taxonomic groups made up an average of $\sim 90 \%$ of total planktonic meta- zoan biomass in our survey lakes, we infer that the strong correlation of mean crustacean species richness and lake production likely holds for other members of the invertebrate community (e.g., rotifers).

Our study did not identify the unimodal relationship between species richness and lake production sometimes recorded in previous studies (Dodson 2000, Jeppesen et al. 2003), instead revealing linear increases in richness with chl $a$. However, because most Norwegian lakes are oligotrophic, with relatively few highly eutrophic sites, there may have been insufficient variability in lake production to clearly identify the presence of nonlinear responses of species richness that probably would have occurred by including a number of more P-rich lakes. In general, positive relationships between lake productivity and mean zooplankton diversity can arise because increased energy availability for consumers and higher food web complexity can allow more species to coexist (Gaston 2000). Alternately, increased autotroph diversity both in larger and in more nutrient-rich water bodies (Smith et al. 2005) may also offer a richer food niche complexity for consumers. Consistent with this view, parallel analysis of

TABLE 3. Multiple regression model relating mean zooplankton species richness to environmental parameters for 245 Norwegian lakes.

\begin{tabular}{lrccc}
\hline \multicolumn{1}{c}{ Source } & \multicolumn{1}{c}{ SS } & df & $F$ & $P$ \\
\hline $\log (\operatorname{chl} a)$ & 28.184 & 1,188 & 13.627 & $<0.0001$ \\
Fish & 2.140 & 3,188 & 0.340 & NS \\
Altitude & 3.140 & 1,188 & 1.522 & NS \\
Latitude & 0.089 & 1,188 & 0.043 & NS \\
Longitude & 5.793 & 1,188 & 2.786 & NS \\
$\log ($ area $)$ & 0.033 & 1,188 & 0.016 & NS \\
\hline
\end{tabular}

Notes: Interactions are included only when $P<0.05$. Sub$\operatorname{arctic}\left(>65^{\circ} \mathrm{N}\right)$ and subalpine $(>300 \mathrm{~m}$ above sea level) sites are excluded. 

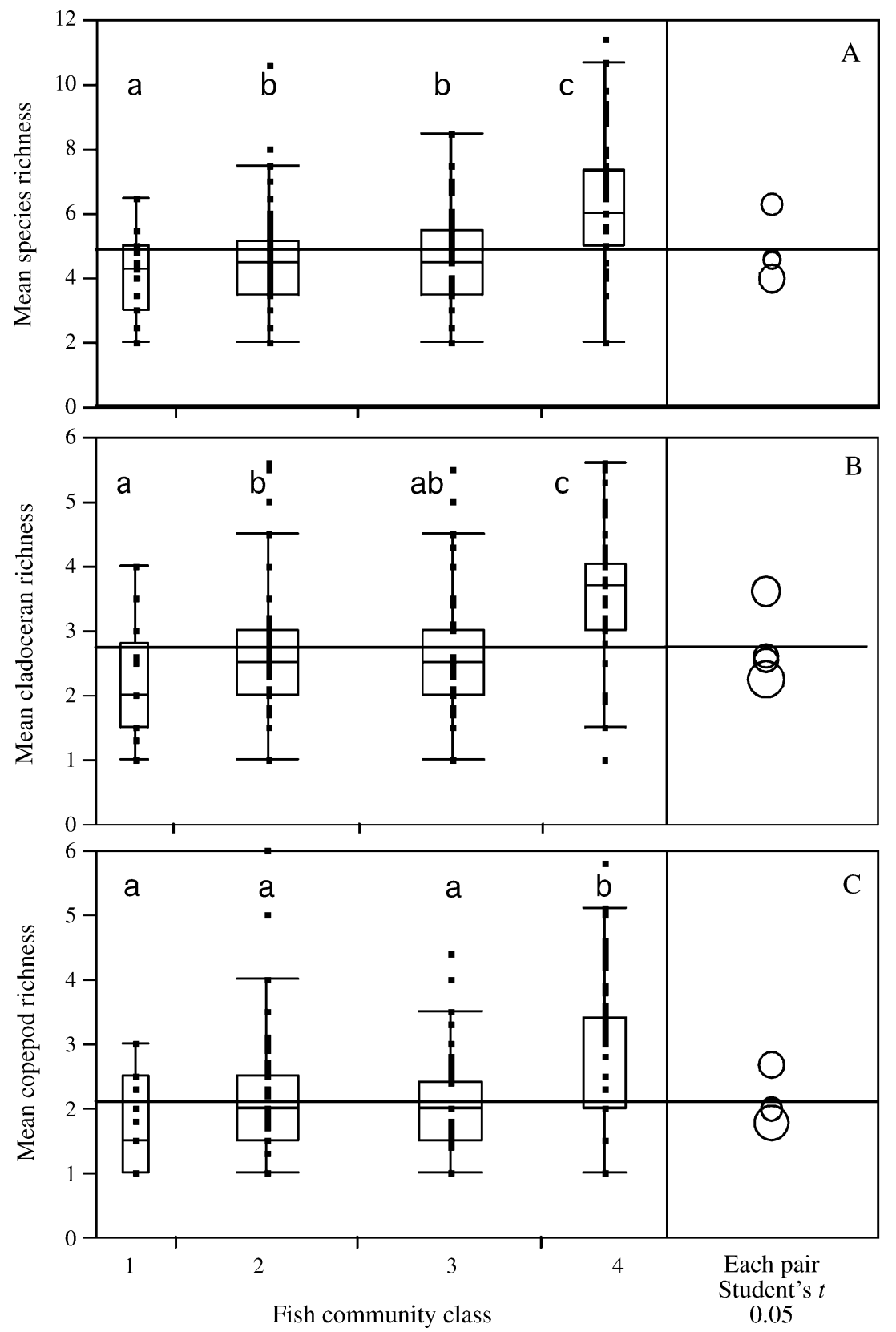

FIG. 6. Box plots of (A) mean zooplankton richness, (B) mean cladoceran richness, and (C) mean copepod richness. Results of pairwise comparisons ( $t$ test) between groups are shown; groups sharing the same lowercase letter are not significantly different from each other $(P<0.01)$. The long horizontal line is the median of all observations, lines within boxes are the medians of the category, the bottoms and tops of the boxes represent 25 th and 75 th percentiles, and extensions of lines are 10th and 90th percentiles. Width of boxes reflects relative sample size. Comparison circles for Student's $t$ test in the right-hand panels indicate significant differences between pairs of samples when the area of intersection between circles is less than 10\%. See Materials and methods: Zooplankton methods for descriptions of each class.

algal diversity in our study lakes revealed higher phytoplankton richness and variability in nutrient rich lakes (D. Hessen, unpublished data).

Although zooplankton biomass was strongly correlated both with productivity ( $\operatorname{chl} a$ ) and zooplankton richness $(P<0.0001)$, we infer that diversity increased mainly as a function of production because there was no strict dependency between biomass and species richness (Fig. 3). For example, fishless water bodies like many of the Arctic ponds and lakes at high latitudes and altitudes may have very high densities that are almost monocultures of Daphnia species (Hessen et al. 2004). In these cases, total zooplankton biomass is clearly unrelated to species richness, although further research will 
be required to establish how this relationship will be modified by presence of vertebrate planktivores.

\section{Role of fish predation}

Several lines of evidence suggest that the positive effect of lake production on crustacean species richness may also have been influenced by variability in fish community composition. First, lakes within fish class 4 had significantly higher zooplankton species richness than those in the other three fish categories (Fig. 6). Fish communities within class 4 were composed mainly of planktivorous cyprinids, presumably leading to elevated predation intensity and possibly greater release of zooplankton from negative competitive interactions. Second, while class 4 lakes tended to be more productive than other sites, the positive influence of fish community structure on richness remained even following exclusion of lakes with chl $a>10 \mu \mathrm{g} / \mathrm{L}$. Finally, effects of fish on zooplankton species richness were evident only in factorial regression models that included class 4 lakes; fish effects were nonsignificant in the 245 lowland lakes remaining after exclusion of class 4 sites, while fish had no influence on total zooplankton biomass. Taken together, these patterns suggest that elevated zooplanktivory by fish in class 4 lakes increased mean crustacean species richness.

Zooplankton biomass did not differ significantly among the four fish community categories, even though a strong effect of fish on zooplankton species composition and body size distribution have previously been identified previously in class 4 lakes (Hessen et al. 1995). According to food web theory, large-bodied and competitively superior herbivores such as large Daphnia would be expected to have been suppressed by intense vertebrate zooplanktivory, possibly leading to compensatory or indirect food-web responses (cf. Chase et al. 2002).

In summary, by including a large number of lakes covering a wide range of geographic and biological variables, this study revealed a clear hierarchy of parameters that act in concert to regulate zooplankton richness. Overall, lake production measured as algal biomass was the major control of zooplankton richness; however, both total zooplankton biomass and fish community composition apparently contributed to zooplankton diversity. In addition, this study demonstrated that latitude and altitude frame the upper boundary of zooplankton species richness, possibly due to constraints imposed during colonization. Unexpectedly, lake size had a weak negative effect on species richness, even though the ability to identify precise controls of absolute species richness was only moderate ( $>50 \%$ of variance in richness was unexplained). Additional comparative analyses to investigate this unexplained variance are currently in progress.

\section{ACKNOWLEDGMENTS}

We thank Robert K. Colwell and Bror Jonsson for helpful comments and suggestions on the representation of species richness. Part of this work was performed at the Center of Advanced Studies in Oslo, which hosted an international group of scientists working within the theme "Stoichiometry, carbon flow, and population dynamics" during autumn 2003 and spring 2004. We are indebted to our colleagues in this group for fruitful cooperation and discussions. Financial support for data collection was provided by the Norwegian Pollution Authorities, and DOH received grants from Center of Advanced Studies for hosting the group.

\section{Literature Cited}

Arnott, S. E., J. J. Magnuson, and N. D. Yan. 1998. Crustacean zooplankton species richness: single- and multipleyear estimates. Canadian Journal of Fisheries and Aquatic Sciences 55:1573-1582.

Bottrell, H. H., A. Duncan, Z. M. Gliwicz, E. Grygierek, A. Herzig, A. Hillbricht-Ilkowska, H. Kurasawa, P. Larsson, and T. Weglenska. 1976. A review of some problems in zooplankton production studies. Norwegian Journal of Zoology 24:419-456.

Browne, R. A. 1981. Lakes as islands: biogeographic distribution, turnover rates, and species composition in the lakes of central New York. Journal of Biogeography 8:75-83.

Chase, J. M., P. A. Abrams, J. P. Grover, S. Diehl, P. Chesson, R. D. Holt, S. A. Richards, R. M. Nisbet, and T. J. Case. 2002. The interactions between predation and competition: a review and synthesis. Ecology Letters 5:302-315.

Chase, J. M., and M. A. Leibold. 2002. Spatial scale dictates the productivity-biodiversity relationship. Nature 416: 427-430.

Chase, J. M., and W. A. Ryberg. 2004. Connectivity, scaledependence, and the productivity-diversity relationship. Ecology Letters 7:676-683.

Connell, J. 1978. Diversity in tropical rain forests and coral reefs. Science 199:1304-1310.

Currie, D. J. 1991. Energy and large-scale patterns on animalspecies and plant-species richness. American Naturalist 137:27-49.

Dodson, S. I. 1992. Predicting zooplankton species richness. Limnology and Oceanography 37:848-856.

Dodson, S. I., S. E. Arnott, and K. L. Cottingham. 2000. The relationship in lake communities between primary productivity and species richness. Ecology 81:2662-2679.

Dumont, H. J., I. Van de Velde, and S. Dumont. 1975. The dry weight estimate on a selection of cladocera, copepoda and rotifera from the plankton, periphyton and benthos of continental waters. Oecologia 19:75-97.

Flöder, S., and U. Sommer. 1999. Diversity in planktonic communities: an experimental test of the intermediate disturbance hypothesis. Limnology and Oceanography 44: 1114-1119.

Fryer, G. 1985. Crustacean diversity in relation to the size of water bodies: some facts and problems. Freshwater Biology 15:347-361.

Gaston, K. J. 2000. Global patterns in biodiversity. Nature 405:220-227.

Gotelli, N. J., and R. K. Colwell. 2001. Quantifying biodiversity: procedures and pitfalls in the measurement and comparison of species richness. Ecology Letters 4:379391.

Graham, M. H. 2003. Confronting multicollinearity in ecological multiple regressions. Ecology 84:2809-2815.

Havel, J. E., and J. B. Shurin. 2004. Mechanisms, effects, and scales of dispersal in freshwater zooplankton. Limnology and Oceanography 49:1229-1238.

Hessen, D. O., T. Andersen, P. Brettum, and B. Faafeng. 2003. Phytoplankton contribution to sestonic mass and elemental ratios in lakes. Limnology and Oceanography 48:12891296.

Hessen, D. O., P. Blomqvist, G. Dahl-Hansen, S. Drakare, and E. S. Lindström. 2004. Production and food web in- 
teractions of Arctic freshwater plankton and responses on increased DOC. Archiv für Hydrobiologie 159:289-307.

Hessen, D. O., B. A. Faafeng, and T. Andersen. 1995. Replacement of herbivorous zooplankton species along gradients of ecosystem productivity and fish predation pressure. Canadian Journal of Fisheries and Aquatic Sciences 52:733-742.

Hewitt, G. 2000. The genetic legacy of the Quaternary ice age. Nature 405:907-913.

Hillebrand, H. 2003. Opposing effects of grazing and nutrients on diversity. Oikos 100:592-600.

Hobæk, A. 2005. Genetic diversity, phylogeography and hybridization in northern Daphnia. Thesis. University of Bergen, Bergen, Norway.

Hobæk, A., M. Manca, and T. Andersen. 2002. Factors influencing species richness in lacustrine zooplankton. Acta Oecologica 23:155-163.

Hobæk, A., M. Skage, and K. Schwenk. 2004. Daphnia galeata $\times D$. longispina hybrids in western Norway. Hydrobiologia 526:55-62.

Hubbell, S. P. 2001. The unified theory of biodiversity and biogeography. Princeton University Press, Princeton, New Jersey, USA.

Hutchinson, G. E. 1959. Homage to Santa-Rosalia or why are there so many kinds of animals. American Naturalist 93: $145-159$.

Irigolen, X., J. Huisman, and R. P. Harris. 2004. Global biodiversity patterns of marine phytoplankton and zooplankton. Nature 429:863-866.

Jensen, T. C., D. O. Hessen, and B. A. Faafeng. 2001. Biotic and abiotic preferences of cladoceran invader Limnosida frontosa. Hydrobiologia 442:89-99.

Jeppesen, E., J. P. Jensen, C. Jensen, B. Faafeng, D. O. Hessen, M. Søndergaard, T. Lauridsen, P. Brettum, and K Christoffersen. 2003. The impact of nutrient state and lake depth on top-down control in the pelagic zone of lakes: study of 466 lakes from the temperate to the Arctic. Ecosystems 6:313-325.

Leibold, M. A. 1999. Biodiversity and nutrient enrichment in pond plankton communities. Evolutionary Ecology Research 1:73-95.

Mittelbach, G. G., T. L. Darcy Hall, N. J. Dorn, E. A. Garcia C. F. Steiner, and J. M. Wojdak. 2004. The impact of density-independent mortality on species coexistence: an experimental test with zooplankton. Oikos 107:415-421.

Mittelbach, G. G., C. F. Steiner, S. M. Scheiner, K. L. Gross, H. L. Reynolds, R. B. Waide, M. R. Willig, S. Dodson, and L. Gough. 2001. What is the observed relationship between species richness and productivity? Ecology 82:2381-2396.

O’Brien, W. J., M. Barfield, N. D. Bettez, G. M. Gettel, A E. Hershey, M. E. McDonald, M. C. Miller, H. Mooers, J. Pastor, C. Richards, and J. Schuldt. 2004. Physical, chemical, and biotic impacts on arctic zooplankton communities and diversity. Limnology and Oceanography 49:12501261.

Økland, R., T. Økland, and K. Rydgren. 2001. Vegetationenvironment relationships of boreal spruce swamp forests

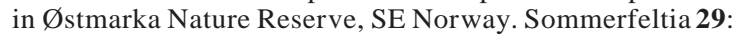
$1-190$.

Paine, R. J. 1966. Food web complexity and species diversity. American Naturalist 100:65-75.

Proulx, M., and A. Mazumder. 1998. Reversal of grazing impact on plant species richness in nutrient-poor vs. nutrient-rich ecosystems. Ecology 79:2581-2592.

Refseth, U. H., C. L. Nesbø, J. E. Stacy, L. A. Vøllestad, E. Fjeld, and K. S. Jakobsen. 1998. Genetic evidence for different migration routes of freshwater fish into Norway revealed by analysis of current perch (Perca fluviatilis) populations in Scandinavia. Molecular Ecology 7:1015-1027.

Rosenzweig, M. L. 1995. Species diversity in space and time. Cambridge University Press, Cambridge, UK.

Schwenk, K., D. Posada, and P. D. N. Hebert. 2000. Molecular systematics of European Hyalodaphnia: the role of contemporary hybridization in ancient species. Proceedings of the Royal Society of London, Series B., Biological Sciences 267:1833-1842.

Shurin, J. B. 2000. Dispersal limitation, invasion resistance, and the structure of pond zooplankton communities. Ecology 81:3074-3086.

Smith, V. H. 1979. Nutrient dependence of primary productivity in lakes. Limnology and Oceanography 24:10511064.

Smith, V. H., B. L. Foster, J. P. Grover, R. D. Holt, M. A. Leibold, and F. deNoyelles, Jr. 2005. Phytoplankton species richness scales consistently from laboratory microcosms to the world's oceans. Proceedings of the Natural Academy of Sciences (USA) 102:4393-4396.

Sokal, R. R., and F. J. Rohlf. 1995. Biometry: the principles and practise of statistics in biological research. Freeman, San Francisco, California, USA.

ter Braak, C. J. F., and I. C. Prentice. 1988. A theory of gradient analysis. Advances in Ecological Research 18: 271-317.

ter Braak, C. J. F., and P. Smilauer. 2002. Reference manual and user's guide to CANOCO for Windows. Software for canonical community ordination, version 4.5. Centre for Biometry, Wageningen, The Netherlands.

Waide, R. B., M. R. Willig, C. F. Steiner, G. Mittelbach, L. Gough, S. Dodson, G. P. Juday, and R. Parmenter. 1999. The relationship between productivity and species richness. Annual Review of Ecology and Systematics 30:257-300.

Whittaker, R. J., K. J. Willis, and R. Field. 2001. Scale and species richness: toward a general, hierarchical theory of species diversity. Journal of Biogeography 28:453-470.

Worm, B., H. K. Lotze, H. Hillebrand, and U. Sommer. 2002. Consumer versus resource control of species diversity and ecosystem functioning. Nature 417:848-851. 